\title{
A molar pregnancy accompanying a living fetus in a twin pregnancy with persistence of the molar pregnancy after uterine evacuation a clinical dilemma with a good outcome: A Case Report
}

\author{
Souzan M. Al Kafy, Abdullah K. Agabawi
}

\section{ABSTRACT}

Introduction: Molar pregnancy as an abnormal gynecological condition and a devastating event to the physician and the mother. Some races have been shown to have a higher incidence of that. Moreover, Incidence have varied between nations. The presence of a molar pregnancy accompanying a normal living fetus is a very rare presentation that is way more devastating to the mother and her physician as it has been associated with many medical problems plus an increased risk of persistence and the development of metastatic disease. Case Report: A 38 -year-old female G5 $P_{3}+1$ who had a previous single cesarean section came from another facility on her 1oth week of gestation as a case of vaginal bleeding which was discovered to be a twin pregnancy containing a normal fetus and an accompanying molar pregnancy. What made it worse is that she developed hyperthyroidism which was very hard to be treated by medications. Her thyroid status

Souzan M. Al Kafy ${ }^{1}$, Abdullah K. Agabawi ${ }^{2}$

Affiliations: ${ }^{1}$ Assistant Professor and Consultant of Reproductive Endocrinology and Infertility, Department of Obstetrics and Gynecology, Medical College, King Abdulaziz University, P.O Box 80215, Jeddah, Saudi Arabia; '2Demonstrator of Obstetrics and Gynecology, Department of Obstetrics and Gynecology, Medical College, King Abdulaziz University, P.O Box 80215, Jeddah, Saudi Arabia.

Corresponding Author: Souzan M. Al Kafy, Assistant Professor and Consultant of Reproductive Endocrinology and Infertility, Department of Obstetrics and Gynecology, Medical College, King Abdulaziz University, P.O Box 80215, Jeddah, Saudi Arabia; Email: sakafy@kau.edu.sa

Received: 03 January 2018

Accepted: 14 June 2018

Published: 26 June 2018 went back to normal after the final treatment. Unfortunately, she went back with persistent disease that was treated with chemotherapy until full recovery. Conclusion: Females who present with such cases are at an extremely high risk of many medical problems that need to be solved in order they get the best management. Treating expectantly may be considered in option in case the mother's life is not at risk and the fetus is well developed. If any risk is present evacuation is the best option. Moreover, persistent disease is another catastrophe that needs to be treated wisely in order to achieve full recovery.

Keywords: Hyperthyroidism, Molar pregnancy, Twin pregnancy, Persistent molar pregnancy

\section{How to cite this article}

Al Kafy SM, Agabawi AK. A molar pregnancy accompanying a living fetus in a twin pregnancy with persistence of the molar pregnancy after uterine evacuation a clinical dilemma with a good outcome: A Case Report. J Case Rep Images Obstet Gynecol 2018;4:100037Zo8SK2018.

Article ID: 100037Zo8SK2018

$$
* * * * * * * *
$$

doi: $10.5348 / 100037 Z 08 S K 2018 C R$

\section{INTRODUCTION}

Molar pregnancy is considered one of the devastating abnormal gynecological conditions that represent a 


\section{EDORIUM Journals}

significant burden as a part of the wide spectrum of gestational trophoblastic diseases. It has been found to be more common in women from South Asia with a higher risk for recurrence in such populations, which also showed some nutritional and socioeconomic factors [1].

Incidence was found to vary between nations and world regions. For instance, it has been shown to be 1 to 2 per 1000 pregnancies in Europe and the United states, which is very low in comparison to Pakistan where the incidence according to one study was found to be 28 per 1000 live births [2][3].

Twin pregnancy with the coexistence of a hydatidiform mole is a rare presentation with a reported incidence of 1 in $22000-100$ ooo pregnancies. This unusual phenomenon is now being seen more commonly due to the rise in ovulation induction [4].

We are reporting a 38-year-old woman G5p3+1 with previous single cesarean section. She came with spontaneous unplanned pregnancy. She presented in her $10^{\text {th }}$ week of gestation as a case of vaginal bleeding which was found to be a twin pregnancy with a one normal fetus and other molar pregnancy. This was treated with suction and curettage. Unfortunately, the patient developed persistent disease that was treated with chemotherapy until full recovery was achieved.

\section{CASE REPORT}

A 38-year-old female $\mathrm{G}_{5} \mathrm{P}_{3}+1$ who had a single cesarean section in her first pregnancy due to failure to progress that is followed by two uncomplicated spontaneous vaginal deliveries. She presented to our institute after being transferred from a private hospital in the same region as a case of twin pregnancy with suspected molar pregnancy.

She was in her usual state of health on her $10^{\text {th }}$ week of gestation until she started to develop a sudden onset of mild vaginal bleeding that was on and off in nature and progressed through out the $10^{\text {th }}$ week in which she started seeking help for her problem. This episode of bleeding was associated with nausea and vomiting of whatever she ate and a subjective complain of palpitation. At the beginning her hemoglobin was 12 which later decreased to 10 in two weeks and eventually to 8.5 after one month.

On gross examination, specimen consisted of multiple fragments of dark brown soft tissue with blood clots measuring $14 \times 13 \times 2 \mathrm{~cm}$ and weighing 200 grams. It showed a grape-like vesicle distended with clear fluid. Fetal part was also identified composed of long and foot. Heel to foot measured $1.2 \mathrm{~cm}$.

Specimen was received in $1 \mathrm{NBF}$ container labeled with the patient's name, hospital number as "placental tissue". It consisted of fragmented placental tissue measuring $10 \times 8 \times 2 \mathrm{~cm}$ in aggregate and weighing 100 grams. Multiple grape-like vesicles were also present. Some of the fragments were covered with fetal membrane. Fetal part was identified without umbilical cord.
Specimen was received in $1 \mathrm{NBF}$ container labeled with patient's name, hospital number as "fetus tissue". It consisted of fragmented fetal tissue composed of head and rip cage measuring $8 \times 4 \times 2 \mathrm{~cm}$ in aggregate. Two fragments of placental tissues were also identified measuring $5 \times 4.5 \times 1 \mathrm{~cm}$ in aggregate.

On microscopic examination, sections revealed markedlylargeedematous chronic villi, somewereshowing central cellular cisterns. Circumferential trophobastic hyperplasia was seen mainly the syscytiotrophoblasts with atypia. Extra-villous trophoblastic proliferation was also noted. Trophoblasts inclusion within the stroma was seen. No normal villi were seen.

Sections from the placental tissue showed normal sized villi without edema. Section from the vesicles showed large edematous villi with circumferential haphazard trophoblasts hyperplasia. Fetal part was identified.

P57 immunohistochemical staining showed negative staining in the villous trophoblastic cells and also in the villous stromal cells. Only extra-villous intermediate trophoblasts are positive. These findings were consistent with complete molar pregnancy. The diagnosis were interpretated as complete mole in molar tissue and placental tissue, while fetal parts were present in placental tissue. Immature placental tissue and fetal parts were identified in the fetal tissue. The fetal parts and the normal placental tissue were from the second twin.

On her $13^{\text {th }}$ week of gestation the plan by her primary consultant was to transfer her to a tertiary center to do more investigations as her ultrasound had shown an accompanied vesicles with a normal living fetus. At our institute a more complicated fetal medicine ultrasound was done and it showed a molar pregnancy accompanying a normal living fetus in the form of twin pregnancy which was confirmed by an MRI (Figure 1). Amniocentesis was done to confirm the diagnosis. During these devastating events, her thyroid hormones where very high resulting in an increase in her heart rate in which it was partially managed medically.

On December the $10^{\text {th }}, 2015$ she was emergently booked for suction and curettage in which the living fetus was extracted and the molar vesicles were sucked. Afterwards, curettage was done to insure the complete evacuation of the uterus. Partial hydatiform mole was assured by histopathology. She tolerated the procedure very well (Figure 2, 3, 4).

At admission, Beta-Human Chorionic Gonadotropin (BHCG) was $798,534(\mathrm{mIU} / \mathrm{ml})$, which dropped very fast two days after the procedure to $15000(\mathrm{mIU} / \mathrm{ml})$. Unfortunately, BHCG started to increase again to 74393 $(\mathrm{mIU} / \mathrm{ml})$ on December the $12^{\text {th }}$ and persisted to increase in which it was $43326(\mathrm{mIU} / \mathrm{ml})$ on December the $20^{\text {th }}$ and $44295(\mathrm{mIU} / \mathrm{ml})$ on December the $27^{\text {th }}$. Immediate oncology consultation was done, as persistent molar pregnancy was the obvious diagnosis then. Luckily, a complete body screening was negative for metastasis.

Under Gynecological oncology care she was started on methotrexate in which she was followed on weekly 


\section{EDORIUM Journals}

J Case Rep Images Obstet Gynecol 2018;4:100037Zo8SK2018.

www.edoriumjournals.com/case-reports/jcrog

bases. On May 23, 2016, five months later and BHCG was negative. Full recovery was achieved after these stressful events and the patient is now living fine.

\section{DISCUSSION}

Molar pregnancy as a gynecological emergency is considered a rare problem that needs to be taken seriously

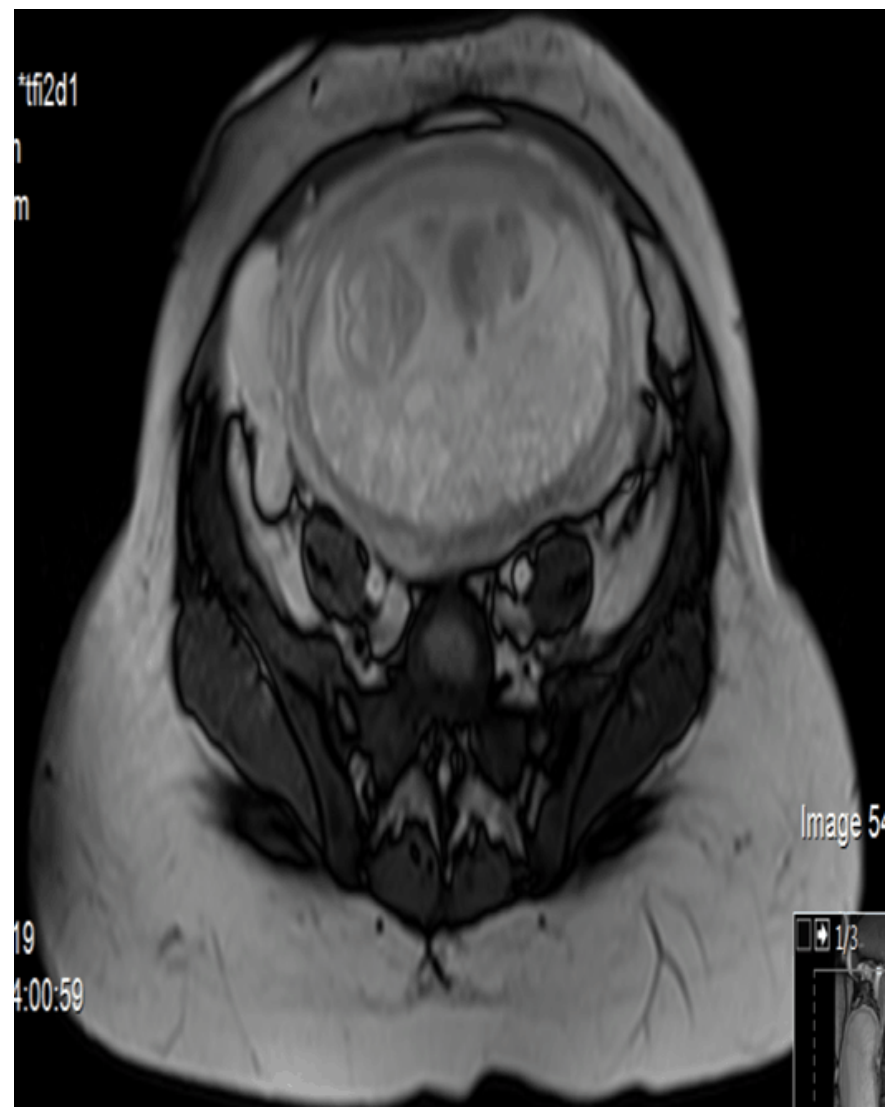

Figure 1: MRI showed a molar pregnancy accompanying a normal living fetus in the form of twin pregnancy.

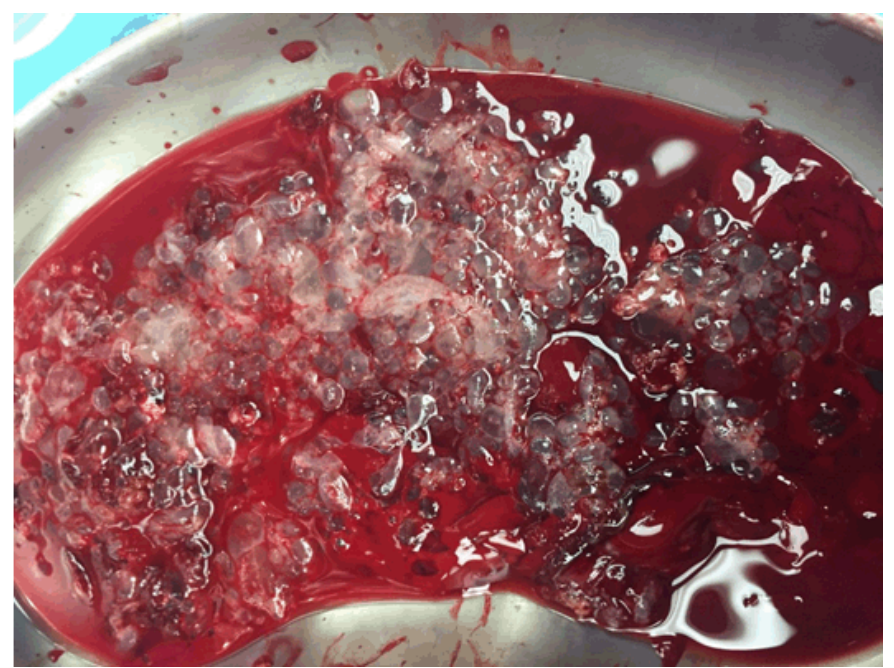

Figure 2: The molar pregnancy vesicles.

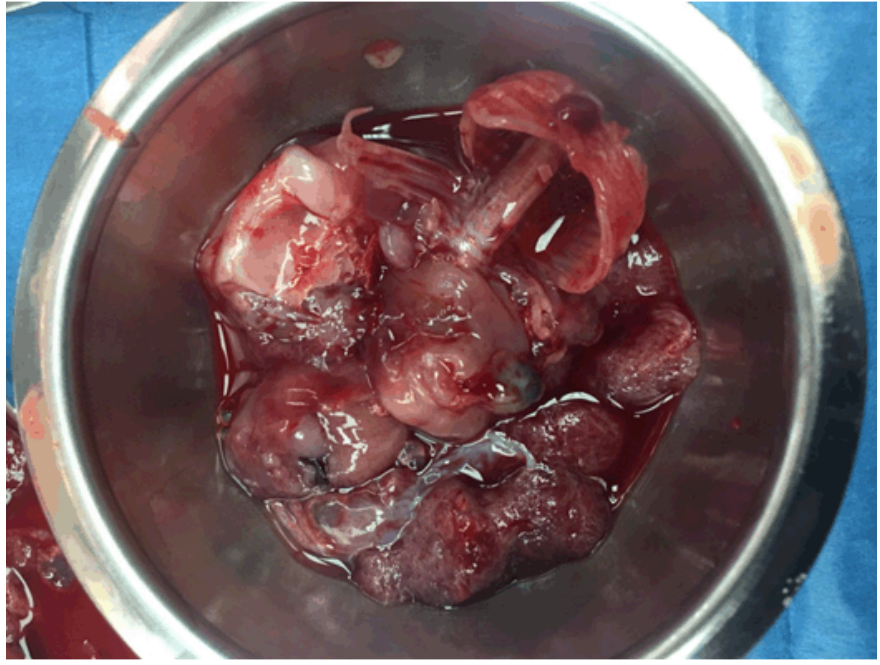

Figure 3: The fetus.

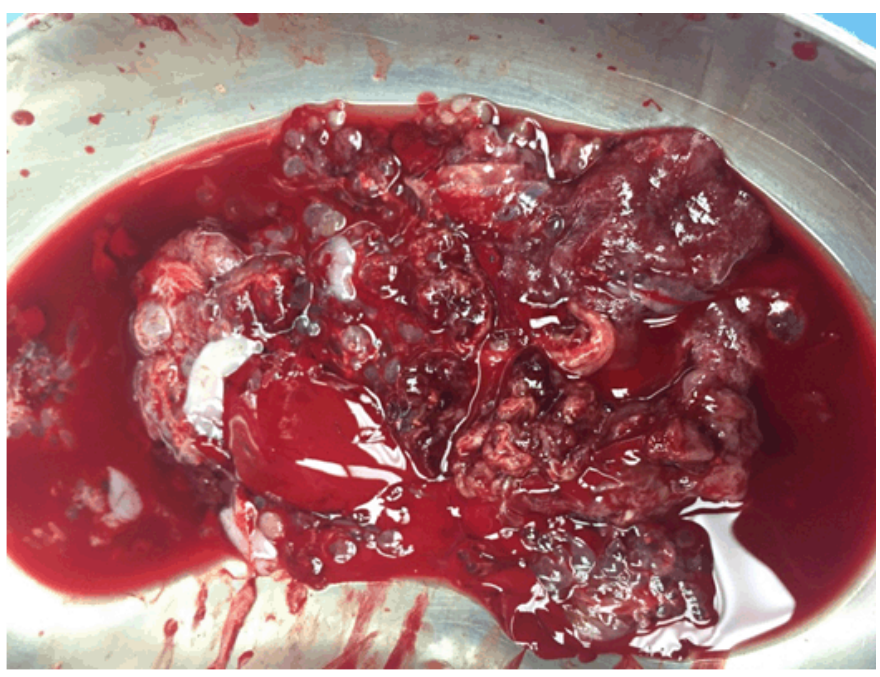

Figure 4: The placental Tissue.

and treated with care. Patients usually present with vaginal bleeding which in rare cases may be accompanied by anemia, uterine enlargement, pre-eclampsia, hyperemesis, hyperthyroidism or even respiratory distress [5]. In our presenting case, the patient was fine until she started to develop complications a sudden onset of hyperthyroidism causing high blood pressure that wasn't responsive to any known antihypertensive medications.

Talking about diagnosis, simple routine first trimester ultrasound with the classical finding of a snow storm appearance within the uterus accompanied by BHCG measurement are the diagnostic methods of this disease [6].

Progression to cancer and distant metastasis are rare complications. It is ideally and safely treated with evacuation precisely suction dilatation and curettage (D\&C) under ultrasound guidance to insure adequate 


\section{EDORiUM Journals}

J Case Rep Images Obstet Gynecol 2018;4:100037Zo8SK2018. www.edoriumjournals.com/case-reports/jcrog

Al Kafy et al. 4

emptying of the uterine contents [7]. BHCG levels should be followed up after evacuation until normal levels are achieved. A rare complication to Molar pregnancy is the Persistent mole that requires chemotherapy (Ex. Methotrexate) and extensive follow up plan to avoid bad sequelae [8]. In our case the patient was found incidentally to have a partial mole accompanying the normal pregnancy after a sudden onset of vaginal bleeding. These pregnancies were found to be associated with a very high risk of preterm labor even though it has been described in literature that many cases reach term and deliver a viable fetus [9].

It has been proposed in the past that the ideal treatment of such cases is termination as there is an increased risk of persistence of the molar pregnancy with some increase in malignancy and metastatic disease that is more than usual molar pregnancies. However, continuation of pregnancy until full term has been accepted as a choice in some cases under some circumstances in which the mother is under conditions of a very precise and well- controlled maternal complications and the presence of a normal healthy living fetus and of course after discussion the options with the patient and getting into agreement with her [10]. In our presenting case, this lady had a lot of devastating events associated with the disease itself so the plan was clearly to evacuate the uterus in order to save the mother's life. The plan was taken by three gynecological consultants and by the recommendations of the medical teams.

According to M.A Stellar Et al, in a case series it has been found that 12 out of 22 patients with a complete mole accompanying a living fetus the mother developed persistent disease with the requirement of chemotherapy of those patients five developed metastatic disease that was treated with multiple cycles of chemotherapy until recovery [9]. Another study described the disease and reported against that in which the risk of a persistent disease after molar pregnancy accompanying a living fetus is the same as singleton molar pregnancy [11]. Persistent disease was an issue in our case in which the patient continued to have the symptoms for a couple of months after evacuation and BHCG was still rising. Accordingly, Gyneoncology recommended starting chemotherapy namely methotrexate in order to treat the disease.

\section{CONCLUSION}

In conclusion, patients who present with molar pregnancy accompanying a living normal pregnancy are at extremely high risk of many medical problems that need to be solved in order to achieve the best management. Expectant management may be considered an option in cases where the mother's life will not be under harm and the fetus is well developed normal living fetus. Whenever there is a risk for the mother evacuation should be done. On the other hand, persistent disease after evacuation is still a devastating event that should be treated wisely in order to avoid progression to metastatic disease.

\section{REFERENCES}

1. Fatima M, Kasi PM, Baloch SN, Kassi M, Marri SM, Kassi M. Incidence, management, and outcome of molar pregnancies at a tertiary care hospital in quetta, pakistan. ISRN Obstet Gynecol 2011;2011:925316.

2. Drake RD, Rao GG, McIntire DD, Miller DS, Schorge JO. Gestational trophoblastic disease among Hispanic women: A 21-year hospital-based study. Gynecol Oncol 2006 Oct;103(1):81-6.

3. Nizam K, Haider G, Memon N, Haider A. Gestational trophoblastic disease: Experience at Nawabshah Hospital. J Ayub Med Coll Abbottabad 2009 JanMar;21(1):94-7.

4. Sebire NJ, Foskett M, Paradinas FJ, et al. Outcome of twin pregnancies with complete hydatidiform mole and healthy co-twin. Lancet 2002 Jun 22;359(9324):2165-6.

5. Hou JL, Wan XR, Xiang Y, Qi QW, Yang XY. Changes of clinical features in hydatidiform mole: Analysis of 113 cases. J Reprod Med 2008 Aug;53(8):629-33.

6. Fowler DJ, Lindsay I, Seckl MJ, Sebire NJ. Histomorphometric features of hydatidiform moles in early pregnancy: Relationship to detectability by ultrasound examination. Ultrasound Obstet Gynecol 2007 Jan;29(1):76-80.

7. Seckl MJ, Sebire NJ, Fisher RA, Golfier F, Massuger L, Sessa C. Gestational trophoblastic disease: ESMO Clinical Practice Guidelines for diagnosis, treatment and follow-up. Ann Oncol 2013 Oct;24 Suppl 6:vi3950.

8. Wielsma S, Kerkmeijer L, Bekkers R, Pyman J, Tan J, Quinn M. Persistent trophoblast disease following partial molar pregnancy. Aust N Z J Obstet Gynaecol 2006 Apr;46(2):119-23.

9. Steller MA, Genest DR, Bernstein MR, Lage JM, Goldstein DP, Berkowitz RS. Clinical features of multiple conception with partial or complete molar pregnancy and coexisting fetuses. J Reprod Med 1994 Mar;39(3):147-54.

10. Matsui H, Sekiya S, Hando T, Wake N, Tomoda Y. Hydatidiform mole coexistent with a twin live fetus: A national collaborative study in Japan. Hum Reprod 2000 Mar;15(3):608-11.

11. Niemann I, Sunde L, Petersen LK. Evaluation of the risk of persistent trophoblastic disease after twin pregnancy with diploid hydatidiform mole and coexisting normal fetus. Am J Obstet Gynecol 2007 Jul;197(1):45.e1-5.

$$
* * * * * * * * *
$$

\section{Author Contributions}

Souzan M. Al Kafy - Substantial contributions to conception and design, Acquisition of data, Analysis and interpretation of data, Drafting the article, Revising it critically for important intellectual content, Final approval of the version to be published

Abdullah K. Agabawi - Substantial contributions to conception and design, Acquisition of data, Analysis and interpretation of data, Drafting the article, Revising it critically for important intellectual content, Final 


\section{EDORIUM Journals}

J Case Rep Images Obstet Gynecol 2018;4:100037Zo8SK2018.

Al Kafy et al. 5 www.edoriumjournals.com/case-reports/jcrog

approval of the version to be published

\section{Guarantor of Submission}

The corresponding author is the guarantor of submission.

\section{Source of Support}

None

\section{Consent Statement}

Written informed consent was obtained from the patient for publication of this case report.

\section{Conflict of Interest}

Authors declare no conflict of interest.

\section{Copyright}

(C) 2018 Souzan M. Al Kafy et al. This article is distributed under the terms of Creative Commons Attribution License which permits unrestricted use, distribution and reproduction in any medium provided the original author(s) and original publisher are properly credited. Please see the copyright policy on the journal website for more information.
Access full text article on other devices

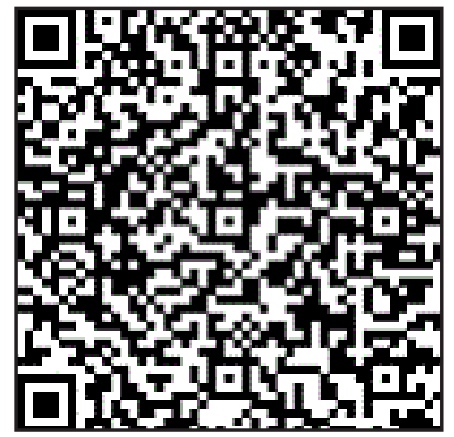

Access PDF of article on other devices

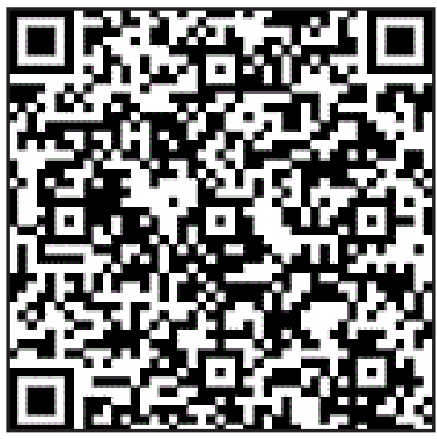

